Covered in: Web of Sciences (WOS); EBSCO; ERIH+; Google Scholar; Index Copernicus; Ideas RePeC; Econpapers; Socionet; CEEOL; Ulrich ProQuest; Cabell, Journalseek; Scipio; Philpapers; SHERPA/RoMEO repositories; KVK; WorldCat; CrossRef; CrossCheck

\section{The Importance of Public Health Policies in the Social - Economic Development of Romania}

\section{Mihaela TOMAZIU- TODOSIA ${ }^{1}$}

${ }^{1}$ Alexandru Ioan Cuza University of Iaşi, Romania, mihaela.tomaziu@gmail.com
Abstract: For each individual, as well as for the entire community, health is one of the most important factors that ensure life and activity. Health care is not only a problem of healthcare but also a problem of a profound social nature, making it an integral part of all the social and economic development conditions. The right to health is conditioned by the health system and the socio-economic factors, which are reflected in the health of the population. The way in which this system is organized is a determinant of the individual's and community's health, putting their mark on the whole of their lives. Human health seen in the concept of public health is based on the individual's health as a component of the health of the population. Areas of approaches are diverse and start from existing health problems such as the state of the environment, socio-economic development or political governance. To ensure health protection, the governments of the world tend to include health in development programs through public policy. This article aims to bring to the attention of readers the importance of social and economic development and the importance of public health policies in this respect. Also, the inequalities existing in Romania regarding access to health services are an area of general interest, as it affects society as a whole.

Keywords: health policies; development; bealth determinants; inequalities.

How to cite: Tomaziu- Todosia, M. (2019). The Importance of Public Health Policies in the Social Economic Development of Romania. Postmodern Openings, 10(2), 162-172. doi:10.18662/po/78 



\section{Introduction}

Health and well-being are key factors in social and economic development, as well as a major priority for the lives of all individuals, families, and communities. Poor health, however, generates the loss of work potential, scattering resources in all sectors.

The field of public policy research was also has been approached in postmodernism and is an area of the boundary between several fundamental sciences, such as political science, sociological economy, social psychology. Public policy science is a relatively recent discipline that originally emerged in North America and then in Europe. Public policies include measures that address the issues that shape the social context.

The level of development of a state is closely linked to the commitment of its members that every individual has a basic element of development and survival. Implementing these commitments on the welfare of members of society is achieved through public policies. The health status of the population is strongly influenced by multiple socio-economic dimensions such as income levels, living conditions, and utilities, labor market situation, quality of health and education services, etc. Thus, under the influence of these factors, the phenomenon of inequalities in accessing the healthcare sector, which is essential for the good development of the society, is based on the health of each individual.

Health status can be approached individually as an essential component of human capital, giving people the ability to carry out they are professional, domestic and recreational activities, to achieve their goals and to pursue their aspirations; at the level of society, health is the key element of human capital, contributing to good development.

\section{Research Methods}

The research methodology involves qualitative research, namely inventory of specialized literature, and quantitative research, using data from official sources, www.insse.ro. For accessibility assessment, proximity indicators were identified to identify possible population groups and/or disadvantaged geographic areas for access to services for which target policies should be developed. The determinants that influence the accessibility of the population to health services are generally represented by the level of poverty, unemployment, occupation, the residence environment, the status of insured in the social health insurance system, and the degree of medical staff coverage. 


\section{The purpose of public health policy in Romania}

One of the main goals of health policies is to achieve a high level of health of the population through a fair distribution of healthcare services. (Wilkinson \& Marmot, 2003, p. 7). This is important, given that health conditions employment, which leads to the economic growth of a state. Another objective is equitable funding, in which spending reflects the ability to pay, and not necessarily the risk of illness of the population. (Wilkinson \& Marmot, 2003, p. 16).

Health policies contribute to changing health at both individual and community level. Through public policies, the state intervenes in the economic and social activity of citizens, modifying the identified reality in a direction dictated by the needs of civil society. The reasons for this intervention can be grouped into two broad categories: (1) Firstly, public policies intervene to correct the action of the free market, because the market has limitations, noncompliances, imperfections; (2) on the other hand, socially accepted values are promoted through public policies, for example, the values that are important in a modern democratic society, such as freedom, equality, justice, etc. (Adams, Amos, \& Munro, 2002, pp. 131 133).

At European level, through the development of a European Health Policy Framework, action is being taken to increase the health and wellbeing of the population by pursuing high-health and health-promoting goals by: (1) Promoting health, preventing disease and fostering the development of a living environment conducive to a healthy lifestyle; (2) Protecting European citizens against serious cross-border threats to health under current conditions; (3) Contribute to the development of health systems in the European Union countries that are efficient, innovative and sustainable; (4) Facilitating citizens' access to safer and better healthcare. (Smith, Ginelly, \& Sculpher, 2005, pp. $248-251)$.

Analysis of health policies follows the cycle of public policy development and implementation. The Ministry of Health plays an important role in the development of public health policies. The policies developed and the strategies developed by the Ministry of Health align with the National Development Plan and the National Public Health Strategy, as well as the Government Program. Public health policies have as their primary role the improvement of the health status of the population, with the access of all citizens of Romania, regardless of their ability to pay. The Ministry of Health prepares, coordinates and implements national health programs and their objectives are established together with the National 
Health Insurance House, the Romanian College of Physicians, representatives of the professional medical associations in the medical field, with representatives of the university clinics, research units, trade unions, non-governmental organizations and representatives of health care system beneficiaries. (Vlad, 2016, pp. 5 -6).

Policy evaluation is the stage that closes the public policy cycle. By definition, the feedback transmits the feedback response generated by the effects of that public policy, triggering a new cycle: the assessment of a political decision influences the actions of the political actors and their agenda, initiating a new cycle that will end with a new decision. The first sign that the assessment takes place is the fact that the law is constantly altered. Policy assessment can be done in three ways: administrative, legal and political assessment; they differ in how they are conducted, through the actors involved and their effects. (Blane, Brunner, \& Wilkinson, 2003, pp. 32 $-38)$.

\section{Public policies as determinants of health}

Health determinants are defined by Last (2005) as "causes and factors that can influence the risk of illness". (Last, 2005, p. 86). Health policies can interfere with health through health determinants, acting at the level of behavior and attitudes of the population, at the level of development of medical services at various levels, namely primary, secondary and tertiary. (Last, 2005, p. 88). Good health is an important resource for all sectors and civil society as a whole, and its benefit is invaluable. Health and well-being intervene in social and economic development, both at the individual and at the community level is recognized as key factors and as a major priority for all the world's countries. All the factors contributing to the development of society intervene in the health of the population, and public policies that take this aspect into account are more effective.

Determinants of health can be influenced by promoting health and prevention at the individual level, plus community efforts. Factors influencing health care can be changed through early diagnosis and screening, as well as by patient or community involvement. The most important factors that negatively affect health include poverty, lifestyle, unemployment, inadequate housing, poor education of the population, pollution of the environment. Their approach at the national level, with appropriate interventions at the Community level, should be based on programs and projects in which public and private resources in the community are used. (Blas \& Kurup, 2010, pp. 261 - 265). 


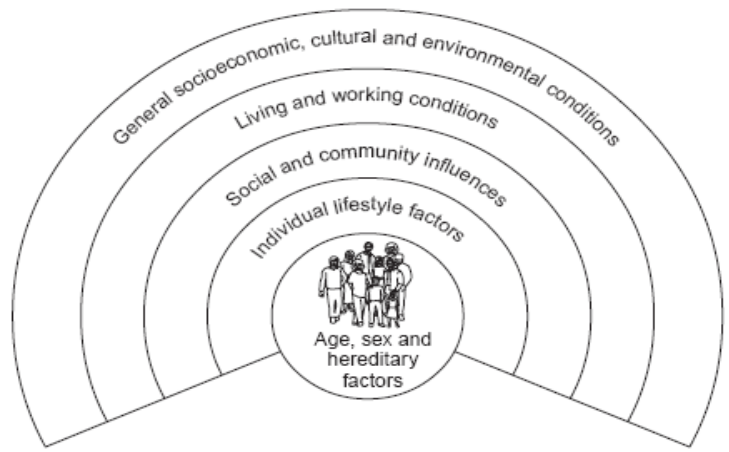

Figure 1: The main determinants of health Source: Adams et al, 2002, p. 95

Health policies are multisectoral, not just health services, but extend to all policies/plans/strategies/programs of other sectors that have an impact on health. They are one of the determinants of less visible and explored health compared to classical determinants that condition the efficacy and sustainability of interventions on all other determinants of health. (Adams et al, 2002, p. 96).

\section{Health Policies in Postmodern Thinking}

According to Smith (1996), the term "postmodernism" appears for the first time by English painter John Watkins Chapman in 1870, who used the formula "postmodernist painting" to define the European plastic phenomenon after impressionist painting. Today, however, postmodernism appears to be a generous palette in which values, ideas, concepts can be mixed without fear of the consequences of hybrid, unexpected results, because they will, anyway, be appreciated/valued as representative. This may also result from the fact that in the middle of the 20th century the term gains an accelerated evolution, extending in different fields, establishing a new historical stage. Reversal of value poles, taxonomic redefinition of concepts, plus-value crediting of non-value are first-line elements, in the free retraction of postmodernity according to its social results.

Theorists, critics and historians often claim that the postmodern is both a logical development, and a reaction against, the modern. This rather complicated assertion can be made more coherent when we state that postmodernity is a logical development of modernity, while postmodernism is a reaction against modernism, as well as some of the distinctive cast of modernity. The following diagram elucidates this complex relationship. 


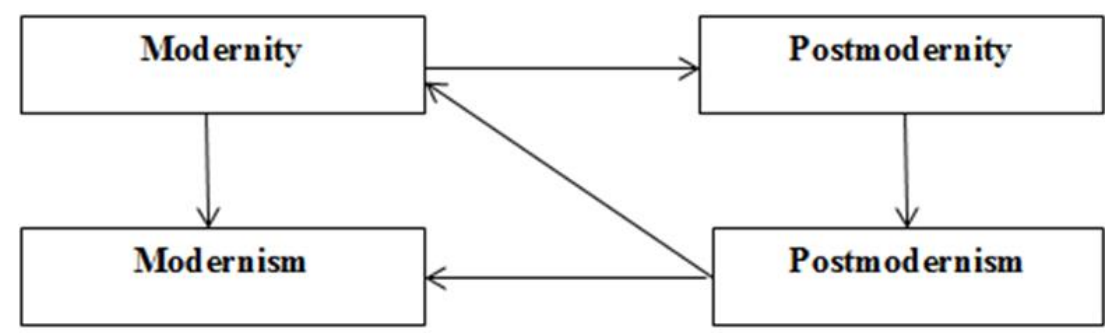

Figure 2: The causal links between modernity, postmodernity, modernism, postmodernism

Source: Delantz, 2000, p. 72

Health policies inspired by postmodern thinking can provide solutions for more efficient functioning of the health care system. The current health system is widely perceived as having serious deficiencies. Expansion costs are considered the main cause of these problems; in particular, increasing health care costs are generated by the need for technology, as any treatment that is technologically feasible should be administered to all patients in need. This is generally the gravity of the fact that spending on health technology is growing twice as fast as economic growth. The concrete conditions of economic development, population structures and morbidity structures specific to each U.K. have, of course, determined health policies that best fit those conditions. (Sarup, 1993, pp. 23 - 29). The experience of some of the countries already trained in the organization and financing of health systems has influenced to a certain extent the evolution of health policies throughout the United States as an integral part of social policies.

Smith (1996) argues that postmodern health policies casts doubt on the belief that the shaping of the world is "organizable" by any organization. It does not accept that any structure can be in rigid control of health care and certainly not of the actions of doctors. Instead of regulating care by providing detailed instructions for the financial settlement of each performance, fees for physicians should be volume-paid in a very simple way: payment per new patient. Internal dynamism will operate between different parts of the health care system and its surroundings to generate its own structures. (Smith, 1996, p. 67). The current health care system is widely perceived to have serious weaknesses. Expanding costs are considered to be the main cause of these problems.

Economically, modern health systems differ according to the number of resources that individuals or society as a whole can allocate to ensure balanced health in a given context, as well as the individual or social 
ability to combine optimize these means in order to obtain the best result. Productivity high enough, as well as the efficient use of available resources, can lead to a high-performance health system.

\section{Inequalities in accessing health services}

Addressing social inequality contributes significantly to health and well-being. Causes of social inequality are complex and deeply rooted in the various stages of human life, exacerbating the disadvantages and vulnerabilities of the population.

Health is currently showing increasing concern about poor health issues both within countries and across the region. The difference between the highest and lowest levels of life expectancy at birth has been in the WHO European Region 16 years, with essential differences between men and women; and maternal mortality rates are 43 times higher in some countries in the region than in others. These extremes of health inequalities are also related to behavioral factors, lack of social protection for people, and poor access to health services. Thus, the health of the population is determined by access to health, on the one hand, and access to health services, on the other. Access to health depends to a large extent on external factors of the health system, namely (1) $10 \%$ social conditions; (2) $8 \%$ medical conditions; (3) 7\% climatic conditions; (4) 15\% hereditary factors; (5) 60\% lifestyle. (,European Health Report”, 2018, pp. 39 - 42).

Accessibility to health care services is determined by the real availability of care facilities compared to real-life demand for health. Disparities in access to care arise for at least four reasons, namely (1) ethnic or racial; (2) economic here, including the direct costs borne by the population, such as co-payments, treatment, and hospitalization costs, and indirect costs such as transport, waiting for times; (3) inadequate geographic location for care facilities; (4) the unequal quality of services of the same type. („European Health Report”, 2018, pp. 45 - 47).

Inequalities in accessing health services have always been present. It is difficult to stop this phenomenon, but with the support of decision-makers, it could be considerably diminished. Inequalities in accessing the health sector are present between rural and urban areas, between the public and the private sector, depending on the possibility of each patient to pay or not the equivalent of the received medical services, as well as between the development areas of Romania. One of the causes is represented by the number of existing healthcare facilities, which makes access to the health check difficult. 


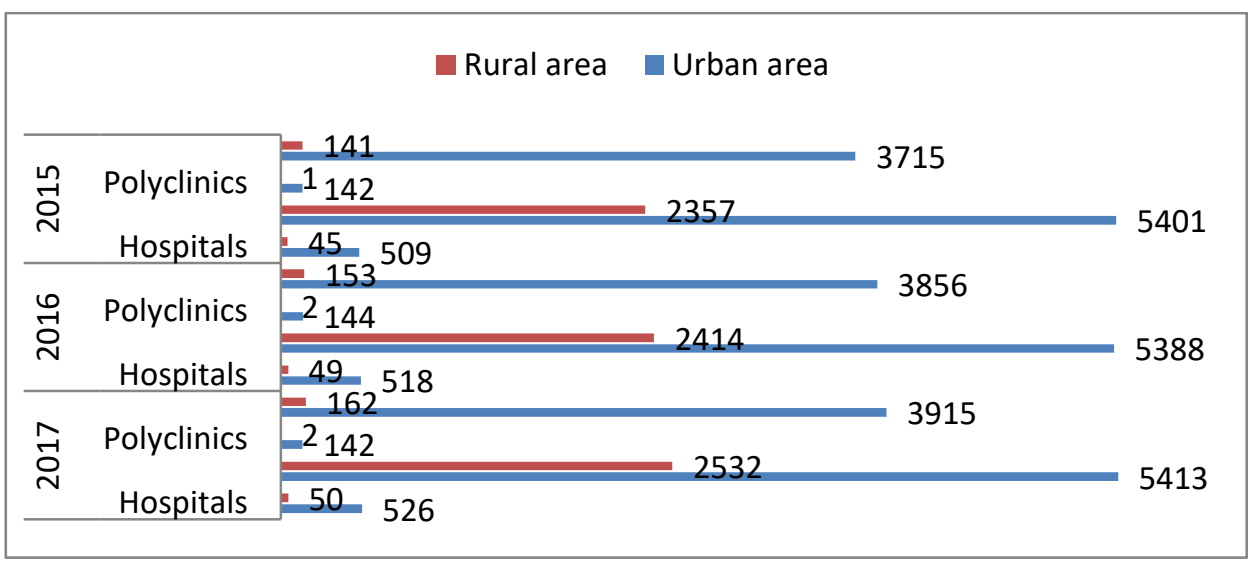

Source: author elaboration based on data from Insse (2017, 2016, 2015)

Figure 3: The number of sanitary units by residence area and unit types

Inequalities between rural and urban areas regarding access to health services have always existed. The lack of certain types of sanitary units, the difficulty of moving in the urban environment, as well as the cost of these journeys, make access to the healthcare sector more difficult. Thus, during the studied period, one can notice the extremely large difference, regarding the number of sanitary units, between rural and urban areas. The number of healthcare facilities in the rural area is increasing but remains insufficient to cover all requests.

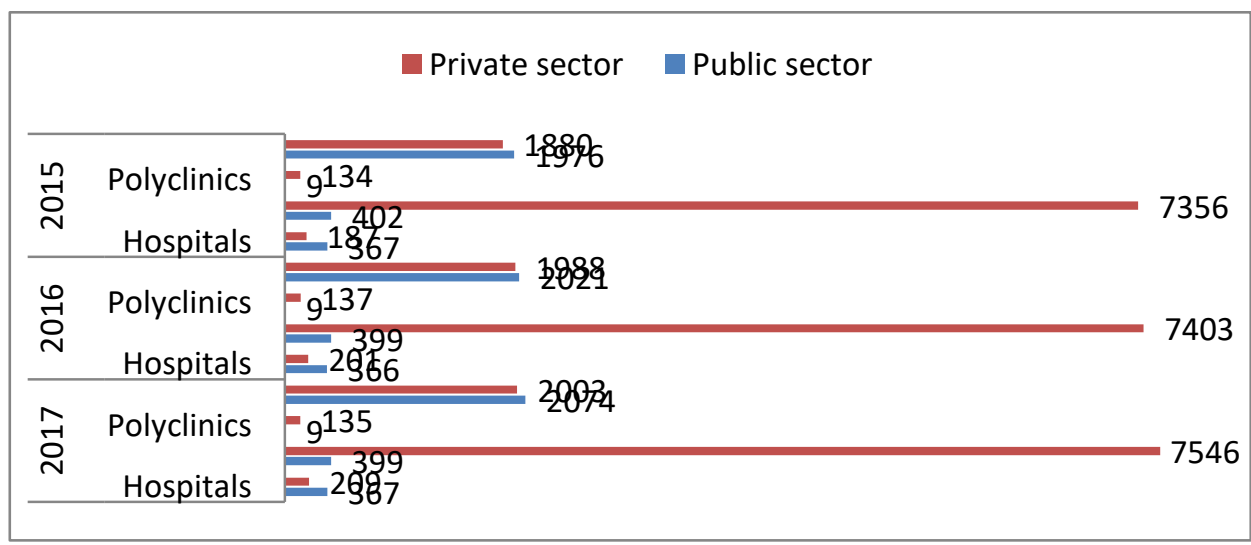

Source: authors' elaboration based on data from Insse $(2017,2016,2015)$

Figure 4: The Number of sanitary units by the form of ownership and types of units 
The inequalities in accessing health services are also a consequence of the number of private health institutions and the public sector. On the one hand, the reduced number of public hospital units leads to waiting lists for patients, limiting and thus hindering access to the sector. On the other hand, the increased number of private health institutions in the private sector allows patients access to health research, but access is conditioned by the possibility for each patient to pay or not to pay for the received medical services.

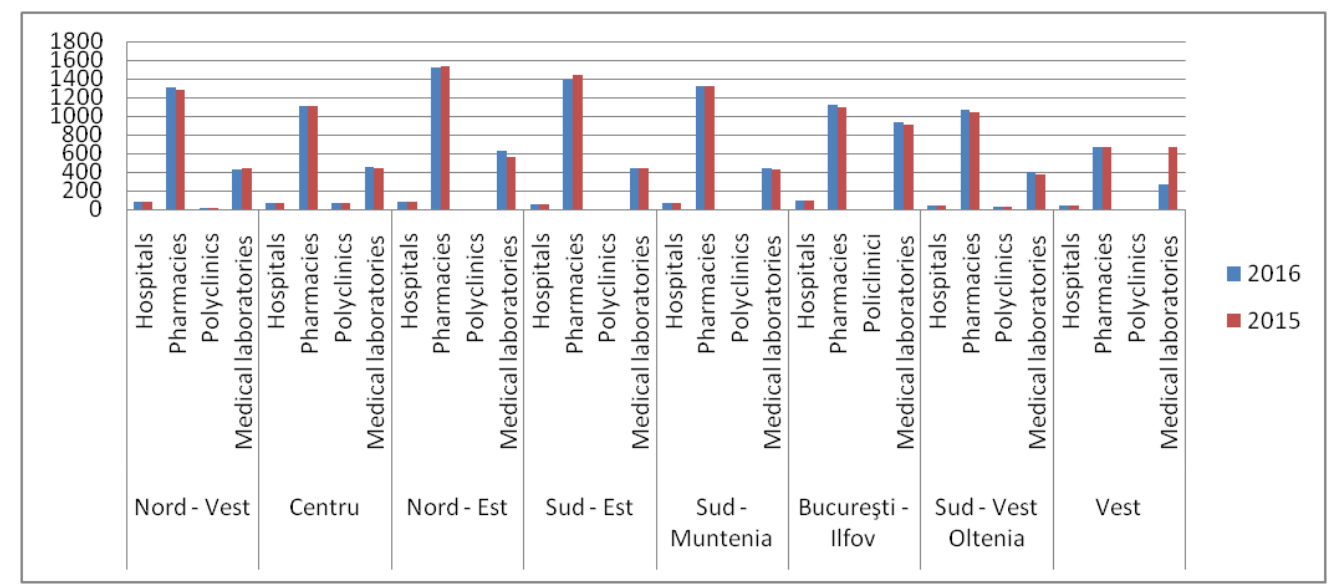

Source: author elaboration based on available data at Insse (2018)

Figure 5: The number of sanitary units by development regions and types of units

It is well known that Romania is confronted with poorer areas and more developed areas, which have a higher number or, on the contrary, a smaller number of sanitary institutions. Thus, during the analyzed years, it can be noticed that the North-East area benefits from the largest number of sanitary institutions, respectively, in 2016, a total of 89 hospitals, 1517 pharmacies, 10 pharmacies, and 623 medical laboratories. The Western Zone faces the lowest number of sanitary institutions in 2016, accounting for 47 hospitals, 664 pharmacies, 4 polyclinics, and 274 medical laboratories.

Taking action on social determinants of health could actually address many inequalities. Research results show that effective interventions need a policy environment that goes beyond sectoral borders and provides the opportunity for implementing integrated programs. In this regard, rural development, which holds account of health determinants is a crucial factor in promoting health and well-being. The participation and accountability of all stakeholders, as well as the provision of sustainable funding mechanisms, lead to the raising of the effectiveness of such local and regional programs. 


\section{Conclusions}

The health of the population is the basis for the development of society. Thus, the areas of approach to factors influencing health are diverse and start from existing health problems, continuing with the state of the environment, socio-economic development, or political governance. To ensure health protection, the governments of the world tend to include health in development programs through public policy.

Maintaining a good lifelong state leads to an increase in healthy life expectancy and a surplus of longevity, both generating important economic, individual, as well as societal benefits. Demographic transformations occurring within countries need an effective strategy that could cover all the stages of life and prioritize new approaches to health promotion and disease prevention.

Improving health and ensuring social equity in health start from ensuring access to health services for all members of society. This sector needs to be available both in urban and rural areas, both in the public and private sectors. The quality and performance of hospitals need to be uniform across all regions of the country, and also to comply with European rules in this regard.

Health policies, based on the principles of involvement and empowerment of all stakeholders, provide real benefits. These include: creating better conditions for strengthening health, improving health care, supporting independent living, and facilitating choices for a healthier lifestyle. These are, in particular, directions of activity such as providing a risk-free task and a healthy start to life; promoting the safety and well-being of children and young people; promoting healthy jobs; as well as supporting healthy aging. Taking into account the epidemic of obesity that spreads across Europe, it is also a priority to provide healthy food and conditions for healthy lifestyle nutrition.

\section{References}

Adams, L., Amos, M., \& Munro, J. (2002). Promoting Health, Politics and Practice. UK: SAGE Publications Ltd.

Blane, D., Brunner, E., \& Wilkinson, R. (2003). Health and social organization, Towards a bealth policy for the twenty-first century. UK: Taylor \& Francis e-Library.

Blas, E., \& Kurup, A. S. (2010). Equity, social determinants and public health programmes. Switzerland: World Health Organization.

Delantz, G. (2000). Modernity and Postmodernity: Knowledge, Power and the Self. London: Sage. 
The Importance of Public Health Policies in the Social - Economic ... Mihaela TOMAZIU- TODOSIA

Insse. (2018). Economic and social landmark regional statistics, [online]. Retrieved from file:///F:/Politici $\% 20 \mathrm{de} \% 20$ sanatate/Repere economice si sociale regio nale statistica teritoriala.pdf [Accessed 08.02.2019]

Insse. (2017). The activity of sanitary units, [online]. Retrieved from

http://www.insse.ro/old/sites/default/files/field/publicatii/activitatea un itatilor sanitare anul 2017.pdf [Accessed 08.02.2019]

Insse. (2016). The activity of sanitary units, [online]. Retrieved from

http://www.insse.ro/cms/sites/default/files/field/publicatii/activitatea u nitatilor sanitare anul 2016.pdf [Accessed 08.02.2019]

Insse. (2015). The activity of sanitary units, [online]. Retrieved from http://www.insse.ro/cms/sites/default/files/field/publicatii/activitatea u nitatilor sanitare anul 2015.pdf [Accessed 08.02.2019]

Last, J. (2005). Understanding the Global Dimensions of Health. UK: Springer Science, Business Media, Inc.

Sarup, M. (1993). An Introductory Guide to Post-Structuralism and Postmodernism. New York: Harvester Wheatsheaf.

Smith, G. B. (1996). Nietzsche, Heidegger and the Transition to Postmodernity. Chicago: University of Chicago Press.

Smith, P. C., Ginnelly, L., \& Sculpher, M. (2005). Health Policy and Economics: Opportunities and Challenges. USA: Open University Press.

Vlad, D. (2016). Analysis of Public Health Policies and the Use of Preventive Services - PhD thesis, University of Medicine and Pharmacy "Carol Davila" Bucuresti.

Wilkinson, R., \& Marmot, M. (2003). Social Determinants of Health, The Solid Facts, Second Edition. Denmark: World Health Organization.

World Health Organization. (2018). European Health Report 2018, [online]. Retrieved from

http://www.euro.who.int/ data/assets/pdf file/0008/379862/who-ehr2018-eng.pdf?ua=1 [Accessed 08.02.2019] 